\title{
European Union Notified Body
}

National Cancer Institute

\section{Source}

National Cancer Institute. European Union Notified Body. NCI Thesaurus. Code C142545.

An org anization designated by an EU country to assess the conformity of certain

products before being placed on the market. These bodies carry out tasks related to

conformity assessment procedures. 